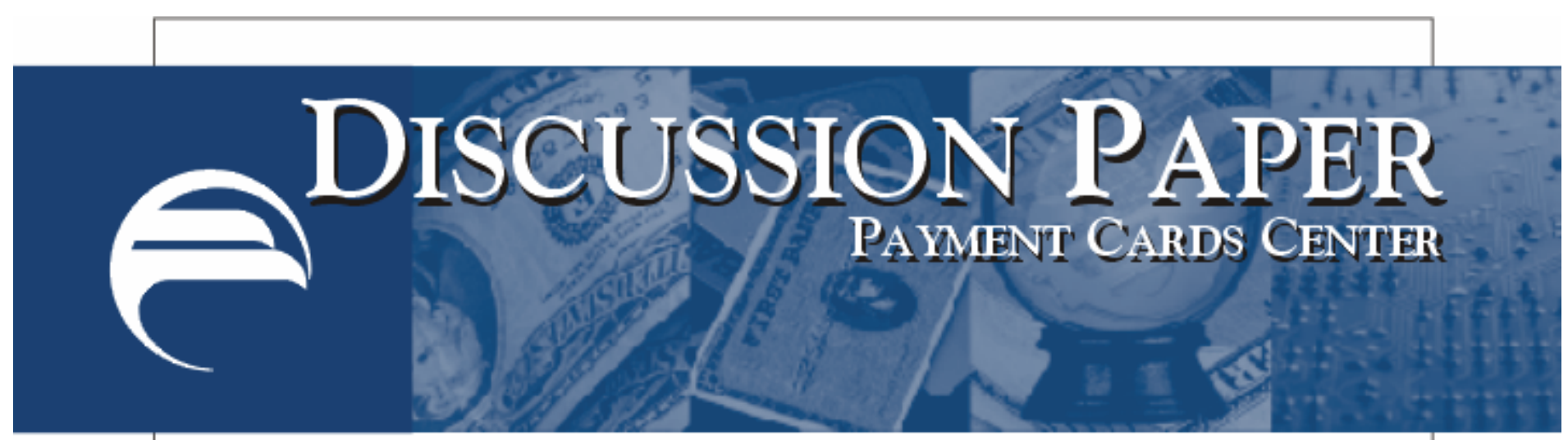

\title{
Prepaid Card Models: A Study in Diversity
}

\author{
Julia S. Cheney*
}

March 2005

Summary: On January 13, 2005, the Payment Cards Center of the Federal Reserve Bank of Philadelphia sponsored a workshop led by Gary Palmer, chief operating officer and co-founder of WildCard Systems, to examine the developing market for prepaid card products. Palmer described several distinct types of prepaid card value propositions, each with its own set of operational needs and customer servicing requirements. In addition, Palmer described new roles that exist in prepaid card programs that are not present in traditional credit and debit card programs. He emphasized that the variety of these programs' requirements and the breadth of thirdparty participants create complexities not only in the servicing of these accounts but also in the economics of these programs and the regulation of this payments category.

* The views expressed here are not necessarily those of this Reserve Bank or of the Federal Reserve System.

\section{FEDERAL Reserve BANK of PHILAdELPHIA}




\section{Introduction}

On January 13, 2005, the Payment Cards Center (PCC) hosted a workshop led by Gary Palmer, chief operating officer and co-founder of WildCard Systems, ${ }^{1}$ to examine developments in the emerging market of prepaid cards. Palmer focused much of his discussion on probing the implications presented by the number and variety of products developing within this payments category. The range of customization available, for example, in product functionality and program servicing, makes prepaid payment cards very different from bank-issued debit and credit cards. In addition, Palmer noted that nontraditional business partners are often integrated into prepaid card programs and specialized processing companies, such as WildCard Systems, have emerged in support of prepaid business models.

After a short review of the prepaid card market, Palmer's presentation began with a description of a number of different types of prepaid card applications, some of which are generally familiar and several that are still emerging. During his discussion, he emphasized several ways in which the various value propositions underlying these programs lead to operating environments not seen in traditional debit and credit card programs. He discussed in some detail two operational roles often found in prepaid card programs: the distributor and the program, or product, sponsor. He gave several examples of the contributions made by these nontraditional entities in the execution of prepaid card programs. In conclusion, Palmer considered the implications that the variation in prepaid models presents for both the economics and the regulation of this payments category.

\footnotetext{
${ }^{1}$ WildCard Systems was founded in 1997 and is described on its web site as "the global solutions leader in turnkey host-based prepaid cards and custom stored-value products.” The company operates internationally and focuses on servicing open-system prepaid card products. WildCard Systems' clients include card associations, banks, and commercial businesses to which it offers capabilities in the areas of prepaid card issuance, authorization, settlement, consumer web site management, distributor web site management, bilingual customer service, and fraud, risk, and compliance services. To obtain more information about WildCard Systems, visit http://corporate.wildcardsystems.com.
} 


\section{A Short Review of the Prepaid Card Market}

The first nonphone-card prepaid programs were launched in the mid-1990s by national retailers such as Blockbuster Video and Kmart. ${ }^{2}$ Their motivation was to replace paper-based gift certificates with lower cost, electronic payment cards that also provided improved tracking of balances and redemption. The processing systems required to authorize and settle the transaction did not run on debit and credit card national payment networks but, instead, leveraged third-party processors to support the unique operational requirements of these prepaid retailer gift card programs. As so-called closed-loop systems, retailer gift card programs limit the redemption of the card's value to the retail outlets of just one or maybe a few merchants. Retailer gift cards have become quite successful and widely adopted by consumers. In fact, in 2003, retailer gift cards accounted for $\$ 42$ billion, ${ }^{3}$ or more than half of the $\$ 69.5$ billion $^{4}$ in total value loaded on prepaid cards that year.

Palmer’s presentation focused on a discussion of more recently introduced prepaid card programs — including but not limited to a form of gift card — that operate on an "open-system" network. The open-system network is differentiated from the closed-system network by the fact that open-system prepaid cards are branded by a payment card network. ${ }^{5}$ Network branding makes it possible for open-system prepaid cards to be processed using the same "tracks" as traditional debit and credit cards. As a result, these branded prepaid cards are accepted at any merchant that accepts the network brand on the card. For example, a Visa-branded prepaid card can be redeemed by its holder at any merchant that accepts Visa-branded debit cards.

Additionally, some open-system prepaid cards also allow card holders to get cash back as part of

\footnotetext{
2 Tom Locke, “Billions in Gift Cards: First Data Plans to Add Loyalty Feature in '05,” Denver Business Journal, December 10, 2004 print edition

${ }^{3}$ Based on a report by TowerGroup. "Market Share Gains Ahead for Bank-Issued Gift Cards?” TransAct, published by America’s Community Bankers, Spring 2004 Vol. 2, No. 2.

(http://www.americascommunitybankers.com/publications/transact/ta04spring.pdf)

${ }^{4}$ The Nilson Report, Number 823, December 2004, p. 6.

${ }^{5}$ Payment card networks include Visa, MasterCard, American Express, and Discover.
} 
a retail purchase and to withdraw cash from automated teller machines (ATMs) in participating or partner networks.

Importantly, Palmer emphasized that while leveraging existing debit and credit card processing networks is a common attribute of open-system, network-branded prepaid cards (hereafter "prepaid cards”), this shared characteristic does not mean that all such programs are the same, and in fact, he noted that a variety of different prepaid business models have been developed to run on open-system networks. In comparison, closed-system retailer gift card programs focus on a single application: providing a prepaid card product to consumers solely for making purchases at a single merchant or, in some cases, a group of retail merchants.

The day’s workshop dealt specifically with the open-system, network-branded prepaid card programs. As such, the remainder of this paper will begin with a discussion of the range of product applications that exist, and are emerging, in the branded prepaid market along with a description of the unique roles that distributors and program sponsors play in many of these programs. The paper concludes with a summary of three case studies Palmer used to illustrate how product differences affect the economics for issuers of these cards and, last, how these and other differentiating characteristics must be taken into account in shaping the regulation of prepaid cards.

\section{Open-System Prepaid Card Programs Offer a Range of Value Propositions}

Palmer stressed that open-system, network-branded prepaid card programs can vary substantially in how they operate and in the value and functionality they provide to card holders. At the same time, he noted that these prepaid card programs share a common attribute: A card can be funded in advance by a consumer, a corporation, or a government entity and spent later by a card holder. Another shared attribute of prepaid card programs is that they offer issuers and providers the ability to shift traditionally higher cost and time-intensive paper-based systems to cheaper electronic alternatives. At the same time, Palmer noted that these baseline characteristics 
position open-system prepaid card programs to serve a variety of unique consumer and business needs. He emphasized that this payments category is still in the early days of market development and that new applications and innovations are continually emerging. Even so, the market already includes an array of distinct prepaid card programs, all based on the concept of preloaded value and the reduction of costs by means of electronification.

In his discussion, Palmer highlighted several of what he called prepaid card "value proposition verticals.” He noted that some verticals, such as gift cards, payroll cards, and travel cards, are relatively more established in the marketplace. He also described several emerging verticals that he believes have real potential: health-care cards, benefit cards, disaster-relief cards, and incentive cards. He noted that each of these prepaid card verticals services the specific needs of a target market with differing product features. In general, these differences relate to the process to load value onto the card, the functions provided by the card, and the technical and operational requirements to support the card. He emphasized that understanding the uniqueness of these value propositions is a critical factor in building processing systems that are flexible enough to service each vertical and, at the same time, are able to integrate with the traditional payment card networks. Stressing the "one size does not fit all” argument, he suggested that understanding the various prepaid business models is also a key factor in evaluating the economics of these products and in developing appropriate consumer-protection regulations for them.

To illustrate the range of differentiation among prepaid cards, Palmer briefly described several of the more established prepaid card programs - gift cards, payroll cards, and travel cards - and then several newer and emerging applications.

\section{Gift Card Programs}

In his discussion of gift card programs, Palmer again limited his comments to opensystem, network-branded gift card programs (hereafter "gift cards” or "gift card programs”). Gift cards offer the ability to purchase a card-based product with a preloaded, although limited, dollar value that, in turn, is redeemable by the gift receiver anywhere the network brand on the card is 
accepted. Gift cards can be purchased in a range of affordable values (e.g., \$25, \$50, \$100) through several bank-sponsored channels - branches, telephone service numbers, or web sites or directly through payment card networks that are also issuers, such as Discover or American Express. In most cases, the value is loaded onto the card when it is purchased and can be accessed immediately by a card holder. Palmer noted that gift cards represent a majority of the networkbranded prepaid cards issued in the marketplace but, in comparison, account for proportionately less of the total value loaded onto these cards. He attributed this to the fact that gift cards are generally loaded on a one-time basis and for lower values than other applications, such as payroll cards, that can be reloaded multiple times.

As he described, the card's functionality is tailored to meet the demands of gift givers and gift receivers, with a focus on the convenience of buying and loading value to the card, changing ownership of the card (the "gifting"), and redeeming the value on the card. Gift card options may include ATM access as well as a variety of card designs - such as "Happy Birthday” or "Happy Holiday” versions - to provide a degree of personalization of the gift. Additionally, providers may elect to gather customer data about who is using these cards and in what ways. Unlike retailer gift cards, network-branded cards can be redeemed anywhere the card brand is accepted. The network enables card holders to access the card-based funds across multiple retail channels: brick-and-mortar merchants, Internet sites, and catalogs. Further, where personal identification number (PIN) options are available, gift cards may also allow ATM cash withdrawals. Issuers argue that these cards provide a breadth of functionality focused on facilitating a gift-exchange experience not available in the closed-system retail gift card environment.

Gift cards offer value to the purchaser (the "gift giver"), the card holder (the "gift receiver”), and the card issuer. For gift givers, marketing programs emphasize that prepaid gift cards reduce pressure to find the perfect gift. At the same time, gift receivers are able to choose a good or service they value and not just what a particular store offers. In turn, the card issuer has 
the opportunity to earn new revenue from existing customers by offering the gift card as part of its suite of products.

\section{Payroll Card Programs}

Payroll card programs are a mechanism for translating payroll checks into card-based value and, subsequently, to allow the card to be used to access funds, to pay bills, and to make purchases. Palmer said the value-load process is automatic: payroll dollars are transferred from the employer's account to the employee's payroll card account, generally managed via a thirdparty processor. He likened this process to direct deposit of payroll dollars into an employee's bank account but with the value applied directly to the card. Payroll cards are particularly attractive to employees who do not have a traditional banking relationship: the under- and unbanked population. In 2002, estimates showed that 10 million households fell into the unbanked segment and that payroll cards were issued to about 10 percent, or 1 million, of these households. ${ }^{6}$ Given the many advantages associated with payroll cards, many observers anticipate significant growth in the rate of penetration among the unbanked population, with estimates of adoption more than doubling to 25 percent of these households by $2006{ }^{7}$

Palmer described typical payroll card functionality as similar to that provided by a debit card linked to a demand deposit account. Payroll cards provide many of the same functions, including the ability to withdraw cash from ATMs, purchase goods and services at merchant locations, receive cash back as part of a purchase transaction, and access real-time balance information. Palmer emphasized that payroll card support systems must be able not only to provide such card functionality but also to execute program-specific fees. As he noted, there are widespread differences in employer practices as to how various fees for ATM withdrawals,

\footnotetext{
${ }^{6}$ Office of the Comptroller of the Currency, "Payroll Cards: An Innovative Product for Reaching the Unbanked and Underbanked,” October 2003, p. 2. (http://www.occ.treas.gov/cdd/payrollcards.pdf)

${ }^{7}$ Ariana-Michele Moore, "Payroll Cards: A Direct Deposit Solution for the Unbanked," Celent Communications, December 2002. (http://www.celent.com/PressReleases/20021219/PayrollCards.htm)
} 
customer service calls, and so forth are split between the employer and the employee. Support systems must have the flexibility to provide for these customized solutions.

The payroll card provides real value to employees, employers, third-party providers, and card issuers, an important consideration in spurring adoption. Employees without a traditional banking relationship can use the card like any other bank-issued debit card and will generally find it a less expensive way to conduct their financial affairs than the alternative of check-cashing outlets, money orders, and so forth. ${ }^{8}$ Palmer noted that employers are primarily drawn to payroll card programs because of the cost savings associated with moving employees to electronic, rather than paper, payroll disbursements. For example, there is a high administrative cost associated with the physical security of a payroll check as well as the distribution process related to delivering payroll checks to employees. Employers market payroll card programs as another benefit of employment with that particular company. Third-party providers are motivated by the potential to extend relationships beyond payroll processing with valued corporate clients. Bank issuers of payroll cards see such programs not only as a source of new revenue but also as potentially a way to ultimately offer these new “customers” other traditional bank services.

\section{Travel Card Programs}

Palmer observed that prepaid travel cards allow travelers to carry cash in a card-based product that offers many of the same protections and cash accessibility provided by traditional traveler's checks (a market estimated to be over $\$ 30$ billion). ${ }^{9}$ Value is loaded to travel cards in a variety of ways: online, over the telephone, or at distributor locations, such as American Automobile Association (AAA) global offices or bank branches. AAA is a good example of how a bank issuer — in this case, MBNA America Bank, N.A. — can use a third-party partner to

\footnotetext{
${ }^{8}$ Christoslav E. Anguelov, Marianne A. Hilgert, and Jeanne M. Hogarth, "U.S. Consumers and Electronic Banking, 1995 - 2003,” p. 5, Federal Reserve Bulletin, Winter 2004, Federal Reserve Board of Governors. (http://www.federalreserve.gov/pubs/bulletin/2004/winter04_ca.pdf)

9 "Prepaid Cards in Europe and the U.S. 2004," DataMonitor, March 5, 2004. (http://www.datamonitor.com/ ec641c4fc0a346018e7b491430511c27 /industries/research/?pid=BFFS024 3\&type=Brief)
} 
distribute prepaid card products. Travel cards can be used to make purchases at retail merchants and to withdraw funds at ATMs around the world. Bank issuers often emphasize the relative ease with which consumers report the loss or theft of a card and replace it, as opposed to dealing with the traditional paper alternative.

The travel card program's value to consumers is based on convenience. The user needs to carry and safeguard only one card number, not many check numbers. Additionally, several cards may be associated with one account, allowing users to travel with a replacement card, and thereby eliminating the need, if the card is lost or stolen, to have replacements mailed or picked up from a physical location. A call reporting the card as lost or stolen is sufficient. Travel cards can be used anywhere the network sponsor's cards are accepted, including ATMs, and generally are accepted at more point-of-sale locations than are traditional traveler's checks. Issuers enjoy the cost benefits of electronic processing and may gain incremental income from fees (including foreign exchange fees, float, and breakage) as well as from cross-selling additional services to travel card customers. In addition, when third-party distributors are involved, there will be some form of revenue-sharing between the bank that issues the cards and the entity that distributes the cards to end-users.

\section{Emerging Prepaid Card Programs}

To demonstrate the range of prepaid applications and highlight several innovative and emerging solutions, Palmer briefly described cards for health-care coverage, benefits disbursements, disaster relief, and employee-incentive payments.

Prepaid health-care cards are designed to streamline the paper-based claims and reimbursement process for individuals and for insurance providers. Prepaid health-care cards are linked to a health savings account (HSA), with funds contributed by the individual, and in some cases by an employer, to pay for current or future medical expenses. These accounts are provided 
in conjunction with a high-deductible health plan. ${ }^{10}$ Health-care card programs link the prepaid card to the HSA. By doing so, these programs allow consumers to be reimbursed for qualified health-care-related expenses when payment is made to a provider, for example, in a doctor's office. Qualification of expenses and subsequent usage of the prepaid health-care card must be real-time. In this way, the health-care card program eliminates the labor- and paper-intensive, after-the-fact claims submission and reimbursement process. Prepaid health-care cards are seen to offer real convenience and significant cost savings, with benefits for consumers, health-care providers, and HSA sponsors.

Similarly, prepaid benefits cards also streamline the paper-based claims and reimbursement process. But rather than being linked to HSAs, benefits cards are linked to employer-provided flexible spending accounts (FSAs). FSAs are funded by pre-tax payroll contributions and essentially allow employees to pre-pay for qualified expenses, such as those related to health care and transportation, with before-tax dollars. ${ }^{11}$ The employee contributes these funds to the FSA as part of the payroll process, and the money can be applied to a prepaid benefits card. As is the case with health-care cards, purchases made with a prepaid benefits card must be qualified as reimbursable under the FSA program at the point of sale. Further, providers of benefits card programs must comply with Internal Revenue Service (IRS) regulations as to the use of these accounts. For example, they must comply with the rules governing the types of merchants at which these cards can be used. Benefits cards offer advantages similar to those of prepaid health-care cards: convenience, reduced paper processing, and real-time disbursements. In addition, Palmer noted that by making the claims and reimbursement process easier for employees, employers have an opportunity to increase employee participation in FSA programs.

\footnotetext{
${ }^{10}$ For more information on Health Savings Accounts, see http://www.ustreas.gov/offices/publicaffairs/hsa/pdf/hsa-basics.pdf.

${ }^{11}$ For more information on Flexible Spending Accounts, see PCC conference summary "Prepaid Cards: How Do They Function? How Are They Regulated?”, pp. 12-14. (http://www.philadelphiafed.org/pcc/conferences/index.html)
} 
In another application, disaster-relief cards provide a way for disaster-relief organizations to get funds quickly and electronically to those in need. Funds are preloaded onto prepaid cards, and emergency workers distribute these cards to victims. At times, relief-card programs need to verify that the prepaid card funds are redeemed only for qualified purchases or at predetermined merchants. Depending on the program's features, these prepaid cards can support redemption at "network" merchants and provide access to cash via ATMs. The value to individuals lies in the ability to quickly and easily make needed purchases or to access funds after a disaster. Relief agencies are able to quickly get funds to victims who need them and to do so electronically, not through the more costly and time-consuming paper processing of relief disbursements.

The last of the prepaid applications discussed in this section covers corporate incentive programs. Palmer noted that although this type of prepaid card program was actually introduced in the 1990s, incentive cards have been experiencing significant growth in adoption. He attributed this success to the increase in the number of banks offering these programs and the ease with which employers can access such as programs as part of their primary banking relationship. Employers load value to a prepaid card and distribute the cards, rather than paper-based alternatives, to selected employees. These prepaid cards are accepted at network merchants and, many times, also offer the option to withdraw cash from ATMs by entering a PIN. In addition to replacing more costly paper-based alternatives, electronic processing facilitates employers’ record keeping of incentive disbursements and redemptions.

\section{New Players in the Prepaid Value Chain}

In describing the prepaid card verticals, Palmer emphasized that the design of a particular program, including the functionality provided as part of the program, is driven to a great extent by the value proposition offered to consumers and businesses. Very often these prepaid models require the participation of third-party organizations, aside from the bank card issuer. It is the inclusion of these third-party participants that differentiates many prepaid card programs from 
traditional debit or credit card programs. In addition, the need to integrate third-party, and mostly nonbank, participants has given rise to specialized processors, such as WildCard Systems, that have built processing systems with the flexibility to integrate the functions of these nontraditional partners into the traditional processing platforms used by debit and credit card networks.

Palmer highlighted two of these new roles - the distributor and the program or product sponsor - as being unique to a number of the prepaid card applications. The role of distributor was illustrated in the earlier example of AAA, which partners with a card-issuing bank to distribute prepaid travel cards through its own network of branches. AAA is well positioned to market and distribute this bank-issued product and clearly extends the bank’s distribution capability. As described, the distributor's role is to interact with the end-user and to initiate card activation, functions performed only by the bank issuer in the debit and credit card worlds. Traditional debit and credit card processing is not designed to incorporate such third-party distribution functions. In support of such prepaid card programs, WildCard and other specialized processors provide the systems integration between the distributor and the bank issuer.

In addition to third-party distributors, prepaid card programs often include another unique role not present in debit and credit card environments: the program sponsor. Program sponsors are generally nonbank partners that sit between the card issuers and distributors or end-users. These parties “sponsor” the card offering. For example, a payroll card offered by an employer may be a service provided by the employer's payroll processor as part of the payroll processing relationship. In this case, the employer is the distributor of the cards to its employees, and the payroll processor is the program sponsor for an issuing bank. Another example of distributor and program sponsor roles can be found in prepaid benefits card programs where a third-party provider manages employees' flexible spending accounts (FSAs) on behalf of an employer. In this case, the employer serves as the distributor, registering interested employees in the program. The company managing the FSA program is the program sponsor, managing the accounts associated with the enrolled employees and the interaction with the card-issuing bank. Like 
distributors, program sponsors are unique to these programs. In the traditional debit and credit card environments, the issuing bank manages all customer account activity.

\section{Economic Case Studies for Issuers: Gift Cards, Payroll Cards, and Teen Cards}

In his discussion of the economics behind network-branded, prepaid card programs, Palmer stressed two points: the variation of economic drivers among types of prepaid card programs and the financially challenging environment for bank issuers of these products. While not discussed in detail, closed-system retailer gift card programs, Palmer noted, have distinctly different economic drivers. For merchants, a key is the sales "lift”: Recipients of retailer gift cards will often spend more than the designated gift amount, thereby "lifting” sales and profits for the merchants that provide the card. To illustrate the variations in economic drivers among opensystem prepaid programs, Palmer reviewed financial case studies for three representative prepaid card programs: bank-issued gift cards sold on the Internet, payroll cards, and “teen” cards.

Interestingly, in the case of open-system gift cards sold by banks online, the bank issuer is also a merchant in the sense that it is selling the card to the end-user. Therefore, the bank in this case "pays" the card network merchant fees, which are only partly offset by the interchange fee it receives as the card issuer. Initial card fees and other monthly account fees, where permitted by state law, are the principal sources of product revenue. On the cost side, Palmer noted that perhaps because of the newness of the product and its unfamiliarity to consumers, call center and other customer service expenses, marketing costs, and merchant fees (when sold online) are the largest expenses.

The payroll card has its own set of economic characteristics, mostly concerning the relatively large dollars associated with payroll disbursements and the reloadable nature of the product. The large dollar values combined with regular reloading of the card generate greater interchange revenues than do, say, gift cards. Another characteristic of the payroll card is that the fees for such things as ATM withdrawals or statement preparation are often borne jointly by 
employers and employees. On the expense side, Palmer observed that, like gift cards, payroll cards also carry significant customer support costs, largely associated with inbound account servicing calls.

Teen cards are essentially reloadable general purpose prepaid cards, with functionality similar to that of gift cards. Teen cards were developed to give parents the ability to reload value - such as a weekly allowance - onto a prepaid card, for their child (i.e., teenager) to use instead of cash. These cards present an easy way for parents to transfer money to family members who may not have a bank account. In Palmer's experience, the usually low dollar amounts on the cards, the multiple value loads (which trigger merchant processing fees for issuers), and relatively high customer service costs invariably make teen cards a losing economic proposition. Nevertheless, he observes that teen card programs continue to be offered by bank issuers who find the programs are especially popular with their best customers. As such, teen cards' economic value to banks is more closely aligned with the profitability of customer relationships.

In contrasting these three financial pictures, Palmer noted that the value propositions of each model can affect the economic drivers of the products to varying degrees. At the same time, they all seem to be challenged by high fixed costs, particularly those related to operational support, and excessive customer servicing costs. He attributed some of these costs to the newness of prepaid cards and the related need to familiarize consumers with these products. He also noted that prepaid programs generally suffer from a lack of scale and, as a result, increased per unit costs. Some of these costs, he noted, may decline as consumer awareness increases and, of course, as technology providers develop enhancements that will make these products easier to use. For example, as Visa, MasterCard, and Discover enable balance inquiries at the point of sale and as providers enable flexible text messaging to mobile phones to communicate things like value loads or balances that fall below a certain dollar amount, live customer service costs should decline and customer satisfaction with the product should improve. On the revenue side, bank issuers of prepaid cards remain largely dependent on fees associated with card acquisition and 
use. In summary, while issuers face real economic challenges in the prepaid card business, Palmer is confident that the compelling value propositions being developed combined with improving cost structures will ultimately improve the financial picture for many of these prepaid card products.

\section{Regulatory Considerations}

In his closing remarks, Palmer briefly touched on the regulation of prepaid cards and some of the ways in which efforts to develop effective consumer-protection regulations are complicated by the many prepaid card products in the marketplace. He noted that these models introduce different types and degrees of risks for the consumers who use prepaid cards. For example, payroll card holders are substituting a prepaid card for a checking account and are having relatively large dollar amounts regularly deposited to these cards. On the other hand, gift card holders are generally dealing with much smaller dollar values, and in most cases, these cards are not reloaded. In the former case, the consumer's entire paycheck is potentially at risk whereas, in the latter case, the card holder's risk is limited to the preset value on the card. In addition, Palmer noted that regulation of these products is further complicated by the number of regulatory agencies focusing attention on this category of payments, including state, federal, and international stakeholders. ${ }^{12}$ At the end of the day, Palmer stressed that building awareness of the very different prepaid businesses models co-existing in this payments category is key to developing effective consumer-protection regulations for this market.

\footnotetext{
${ }^{12}$ For more information on regulatory considerations related to prepaid cards, see "A Summary of the Roundtable Discussion on Stored-Value Cards and Other Prepaid Products,” Federal Reserve Board of Governors, Payment System Development Committee.(http://www.federalreserve.gov/paymentsystems/storedvalue/default.htm)
} 


\section{Conclusion}

In summary, Palmer described a market of significant opportunity, extending well beyond the scope of "retailer gift cards," reaching consumers with diverse demographics, economic stations, and payments needs. On the one hand, the mix of prepaid card models present management and operational challenges. On the other hand, these products provide a great degree of flexibility in terms of features and functionality that allow prepaid programs to serve a breadth of payments functions. However, this same product flexibility and related operational complexity have, in part, limited product profitability for issuers. Similarly, the wide range of product applications present their own set of challenges for bank regulators that are responsible for ensuring appropriate consumer protections but that are wary of stifling innovation. In the end, Palmer contended that for continued development and the ultimate success of prepaid card programs, it is critical for businesses, issuers, and regulators to understand the ways in which prepaid card value propositions differ and to adjust their processes accordingly. 